\title{
Anti-Human Globulin Preparation
}

National Cancer Institute

\section{Source}

National Cancer Institute. Anti-Human Globulin Preparation. NCI Thesaurus. Code C112931.

A procedure to isolate one or more anti-globulin antibodies from either serum derived from animals immunized with human serum globulins or from fluids harvested from stable immunoglobulin-secreting cell lines. 